\title{
Simulating Construction Process with an Animation
}

\author{
Naai-Jung Shih* \\ * Department of Architecture, National Taiwan Institute of Technology \\ 43, Section 4, Keelung Rd., Taipei, Taiwan, ROC
}

\begin{abstract}
This paper presents an animation which simulates construction process by applying tower cranes to assemble shared steel forms in a site of six buildings. Only two sets of steel forms are provided. The animation is simulated based on the length of a cycle and the number of cycles (a unit period of time) spent for sliding slabs down and moving cranes to next building's location. The first case schedules fours cycles in removing cranes to next site and eight cycles' difference between assembling structures and floors. Each frame is numbered by a cycle of five days. Slabs are slid down at the intervals of twenty-two or twenty-eight floors. Another case reduces the difference between structures and floors to five floors, i.e., structures are built five floors ahead than floors do. The animated result is used as a communication tool between designer and clients. The animation is a keyframe-based simulation that each keyframe consists of a 3D model to represent the status of buildings of a major construction step. The swept area of cranes is also simulated in both cases. In total, almost one hundred frames were made from the excavation of the site to the finish of mechanic tower. The simulated animation is made in two versions to compare the influence of different schedules and arrangements of construction facilities visually.
\end{abstract}

\section{INTRODUCTION}

This paper presents an animation which simulates construction process by applying tower cranes to assemble shared steel forms in a site of six buildings. The design project is proposed by an architectural firm as a large housing development. Fig. 1 shows this site consists of six buildings in dark color. Those buildings are divided into three groups which have different time-lag in construction schedule. Fig. 2 shows a typical floor plan with cores and columns in white color, although actual shape may very in dimensions and floor area. Most part of the cores and columns will be built before sliding forms are applied to slabs. Sliding forms are raised by tower crane and cast slabs downward. Only two sets of steel forms are provided. One of the two sets will be disassembled and moved cross site to cast another group of buildings.

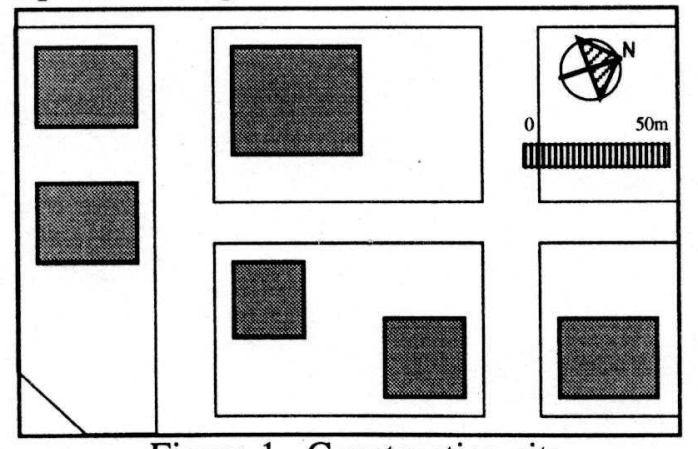

Figure 1. Construction site

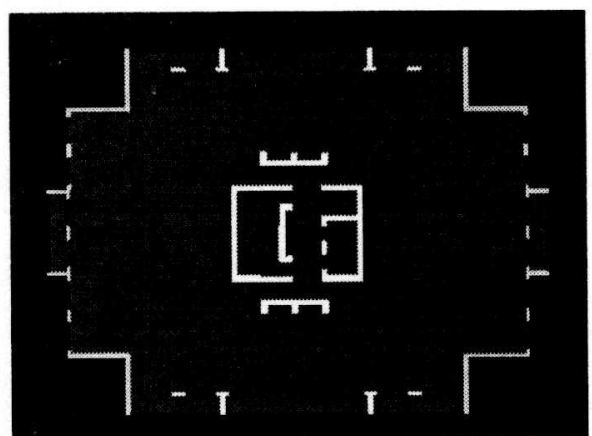

Figure 2. A typical floor plan 


\section{ANIMATION CONCERNS}

Many concerns exist to determine the animation in either programming approach and applying existing applications.[3] In this paper, the concerns lead to use a general animation application to simulate construction space and objects.

- Availability of applications: Former studies have shown that animation can be categorized into many types, even controlled by artificial intelligence.[1,2] Most of the types are the result of the researches conducted in computer graphics. Although many types of animation can be created by commercial packages which are available to architectural firms, some complicated scene can only be controlled by programs. The availability of the programs is very limited, in addition, a medium-sized architectural firm may not afford this type of programs. A firm must determine the trade-off between the level of simulation precision or the amount of investment based on its investment and need. The availability leads most firms to choose a generalized application with pre-defined functions like key-framed animation control.

- Number of parameters: Traditional construction animation must consider many related parameters which are potentially influential. The number of parameters often disables the efficiency in simulation. Although how to simplify parameters remains to be studied, large set of parameters forces a general firm to choose specific application and take a more particular approach in simulating construction process visually. The situation often prevents a even broader acceptance of computer-aided construction simulation as a decisionmaking aid in evaluating the trade-off of different schedules.

- Representation of spatial data: The structural details involved in construction process is very complicated. How to represent the building components and to what detail in threedimensional space has significant influence on the effort in building them in an artificial environment, for example, in a computer as a digit format $[6,8]$. The complexity not only increases computational cost, but extends the time in simulating a new alternative. Decision-making cycle can be prolonged.

- Accessibility of design data in other fields: Strong accessibility enables multi-purposed application of design data to generate more useful analytic information. $[4,5,7]$ A generalized animation application uses objects created by three-dimension functions. Most applications have interactive interface which is very user-friendly. Users, who create threedimension models, can easily conduct animation in multiple tracks. The objects can also be used in other architectural studies. If modeled data can be retrieved from design stages, significant effort can be saved with less modeling cost.

The simulation starts from paper-maneuver that depicts the status in site of each cycle. Computer animation is conducted afterward. The link between the two processes should be scripted and automatically executed. The final simulation process is made by constructing key frame one by one for the availability of applications, number of parameters, and accessibility of design data.

\section{ANIMATION OF CONSTRUCTION PROCESS}

The purpose of the animation is to visualize construction process and the influence of different schedules. In order to provide similar comparison base, the two sets of construction process are conducted with the same components. The buildings are structured by reinforced concrete and built by steel climbing form. Simulated objects include basement excavation, columns, slabs, and tower cranes. The simulated construction stages start from excavation to roofing. In order to reduce modeling variables and accelerate rendering speed, delivering and locating construction members of buildings and forms is not simulated.

The time interval used to measure the unit of construction period is a cycle. A cycle is considered as either four or five days, depending on the type of schedule selected. Cycles' time-lag exists between constructing slab and vertical structures. One of the cycle mentioned here is related to the construction of vertical structures. The time-lag between slab and vertical 
structures is at least forty days, since that period of time is needed to construct slabs form twelfth to second floor.

Sliding form is used to build slab. After columns are elected, forms will be moved to particular floor and casting slabs one beneath another. Fig. 3 shows that columns keep rising while forms keep moving down (cycle 39 and 40) after a slab is built at cycle 38 .

Animated contents in this project are always changing. The modeled environment is not constant, i.e., all the construction members are added one by one, instead of building whole structures and raise from beneath ground. The difference between the animation of pre-defined building and increasing number of structure member made .
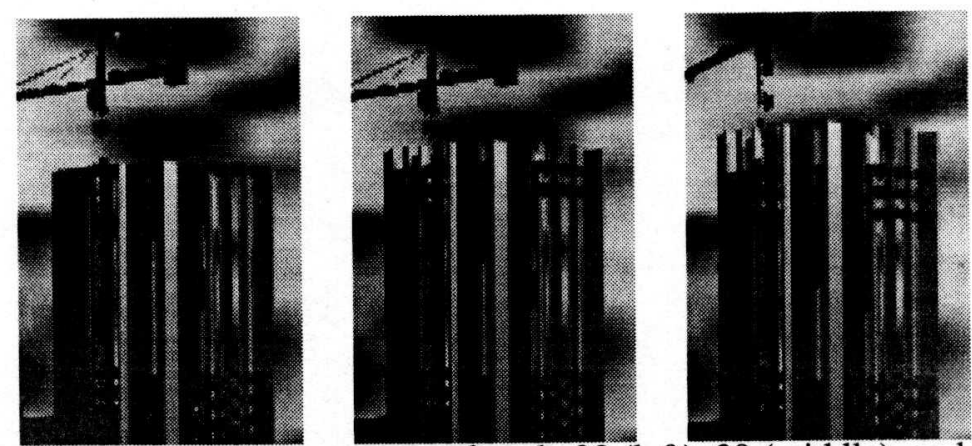

Figure 3. The construction sequence of cycle 38 (left), 39 (middle), and 40 (right)
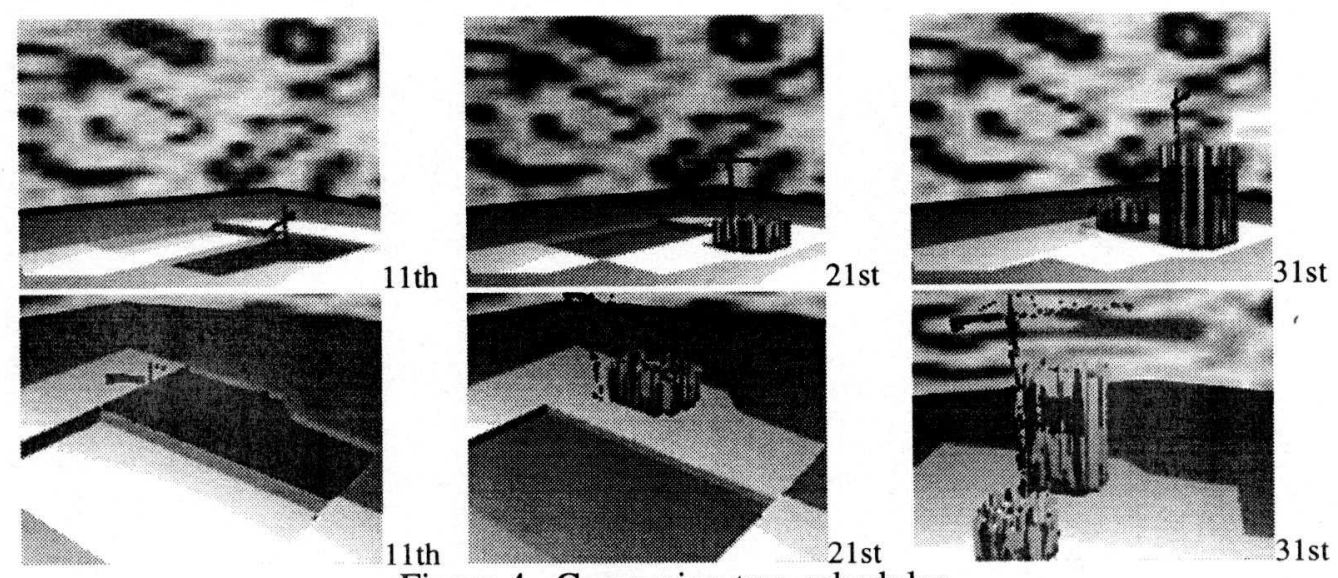

Figure 4. Comparing two schedules

\section{CASES}

Four types of schedules were studies in this site. Two of the schedules were actually simulated and compared (see Fig. 4), since the purpose of animation is to visualize the difference of construction process in different schedules. The left, middle, and right images represent the situation of construction site at the eleventh, twenty-first, and thirty-first cycle. Selected key frames of one animation are shown and explained in Appendix. The appearance of finished building can be seen in Fig. 5 and 6 . The animation is made by a three-dimension modeling and animating application Sculpt 4D on a Macintosh platform.

- Case I: (see Appendix)

- This is the original case. Four cycles are added before steel forms are moved to next site. In the same time, the original tower crane is used to assemble the steel form of the next building for the first cycle. The swept radius of tower crane can reach as far as fifty meters. 
- There are at least eight cycle difference between slabs and vertical structures. Crane should stays at least four cycles after roof is finished and then assemble the steel form of the next building.

- Tower crane has to be moved by mobile crane to next site, although tower crane can

- Case II: be dismounted by itself.

- The slabs cast by steel sliding forms will be constructed downward for every twelve floors, i.e., forms will starts from twelfth floor at the first time. The slab forms are shifted only once by tower crane from the second floor to roof, since most of the buildings are under twelve floors. For the building of twenty-eight-story high, forms will be shifted twice.

- The length of a cycle will be reduced to four days. Crane should stay at least five days after roof is finished, and then move slab forms to ground.

- Case III:

- Reduce the difference between slabs and vertical structures, so slabs are moved down at fifth floor, tenth floor, fifteenth floor, etc. Time-lag between structure and vertical structures would not be too long, and tower crane can be moved earlier. This arrangement makes structure safer, since columns would not be elected without slabs for more than five floors. Nevertheless, the reduced time-lag increases the - Case IV: number of form shift to at least three times for each building.

- An additional crane is added. Each group of buildings will have a tower crane. This arrangement will increase construction cost.

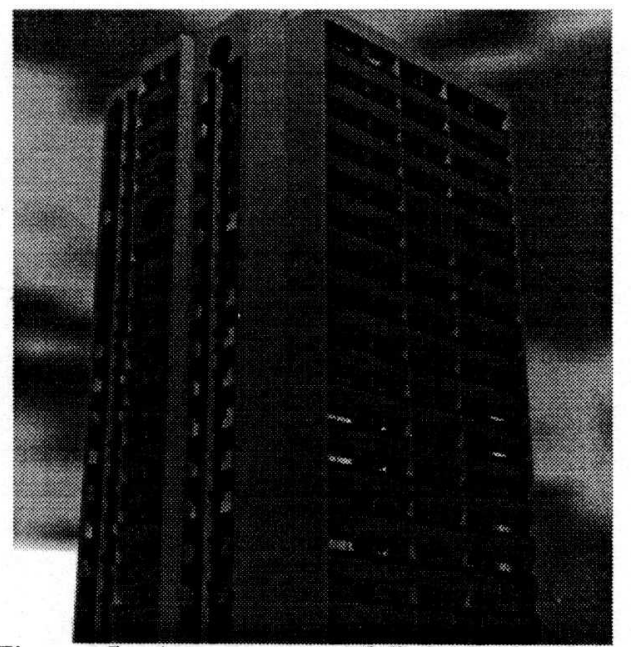

Figure 5. Appearance of finished building

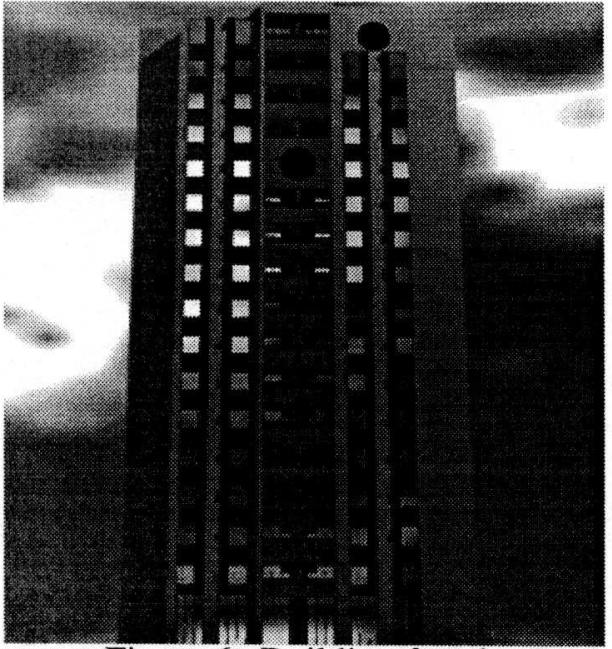

Figure 6. Building facade

\section{PROBLEMS DISCOVERED}

This simulation discovered two problems:

- Clearance: The clearance is measured between the top of steel form and the bottom of counter weight of tower crane. The distance between the top of structure and the bottom of crane was too small. During simulation, the clearance was found reducing, although the height added by columns and crane body follows original construction schedule. The clearance was then enlarged by raising crane body.

- Intervals: The height of columns reached twelve floors (forty-two meters) before slab forms were applied. The simulation showed the columns seemed unable to support slabs 
without bending. In order to reduce the height, the interval of every twelve floors was then changed into every five floors.

\section{CONCLUSION}

The scheduling of construction process is a very complicated task. Instead of trying to simulate all parameters possibly involved, this animation emphasized the inter-relationship between building components like structure member and tower crane. The simulated result was not only able to assist designer evaluating schedule alternatives, but used as a communication tool between designer and clients. Although fully automatic animation was not created from schedules directly, modeling effort should be reduced to achieve more efficient simulation in the future.

\section{ACKNOWLEDGMENT}

Special thanks should be given to Mr. Jung-Che Tsai who offered detailed knowledge in scheduling these buildings.

\section{REFERENCES}

1. Badler, N. I. and Glassner, A. S., "3D Object Modeling," Fundamentals and Overviews of Computer Graphics, SIGGRAPH 93 Course Notes 62, pp. III 1-50, 1993.

2. Foley, J. D., Andries van Dam, Feiner, S. K., and Hughes, J. F., Computer Graphics, principle and practice, 2nd edition, Addison-Wesley, pp. 188-195, 1990.

3. Hendrickson C. and Rehak, D. R., "The Potential of a Virtual Construction Site for Automation Planning and Analysis, Automation and Robotics in Construction X, G. H. Watson, R. L. Tucker, and J. K. Walters (ed.), Elsevier, Amsterdam, 1993.

4. Herbert, Daniel M., "Graphical Processes in Architectural Study Drawings," Journal of Architecture Education, vol. 46, no.1, pp. 188-195, 1990.

5. Kalisperis, L. N., "3D Visualization in Design Education," Proceedings of ACADIA 94, ed. Harfmann, Anton and Fraser, Mike, ACADIA, pp. 177-184, 1994.

6. Lalay Y. E., "Modeling Objects and Environments," John Wiley \& Sons, Inc., New York, 1989.

7. Lawrence, R. J., "Architectural Design Tools: Simulation, Communication and Negotiation" Design Studies, Butterworth-Heinemann, vol.14, no.3, pp. 299-313, 1993.

8. Samet H., "The Design and Analysis of Spatial Data Structures," Addison - Wesley Publishing Co., Inc., New York, 1990.

\section{APPENDIX}

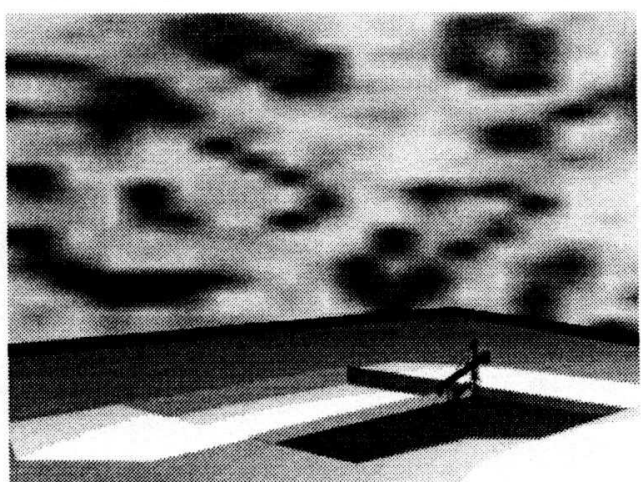

Cycle 11: Excavation of two adjcent lots is shown. One tower crane is used.

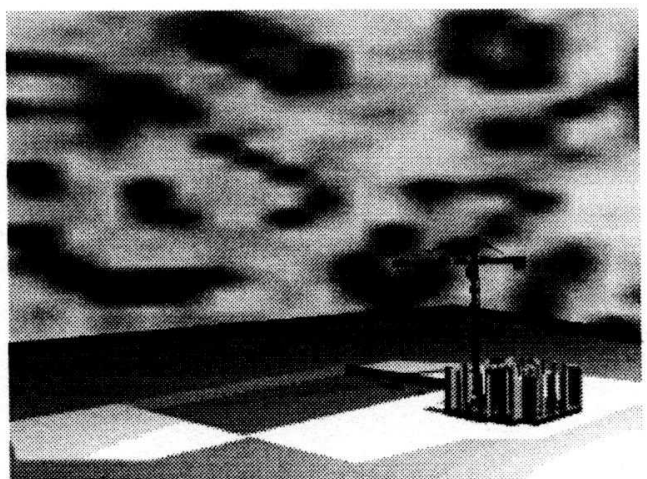

Cycle 21: A building is raising columns, while another is working on basement. 

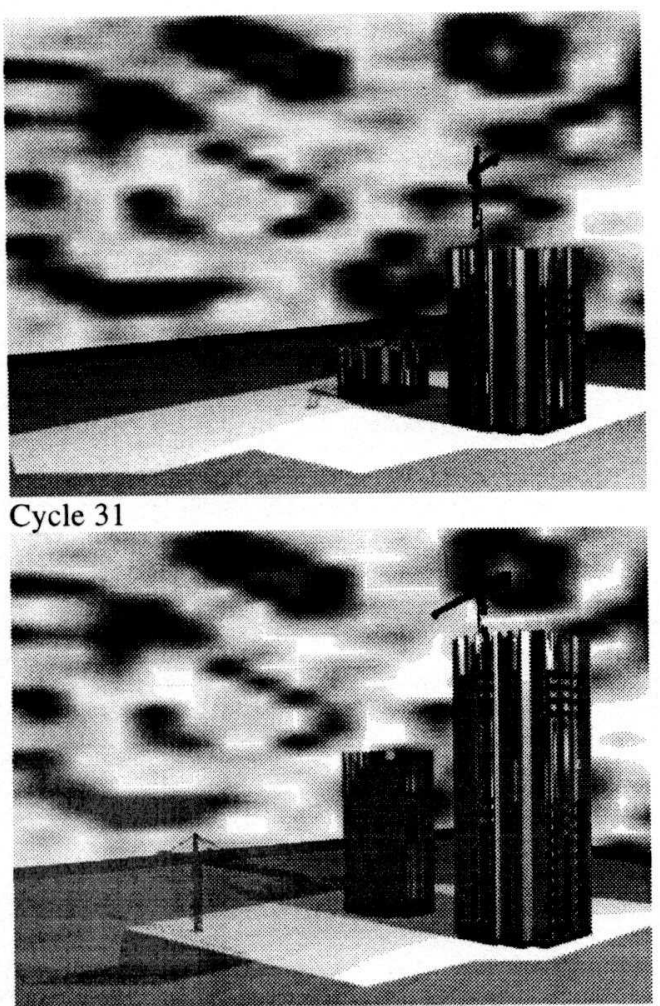

Cycle 41: A new excavation is working on Building to the right is now descending slab forms.
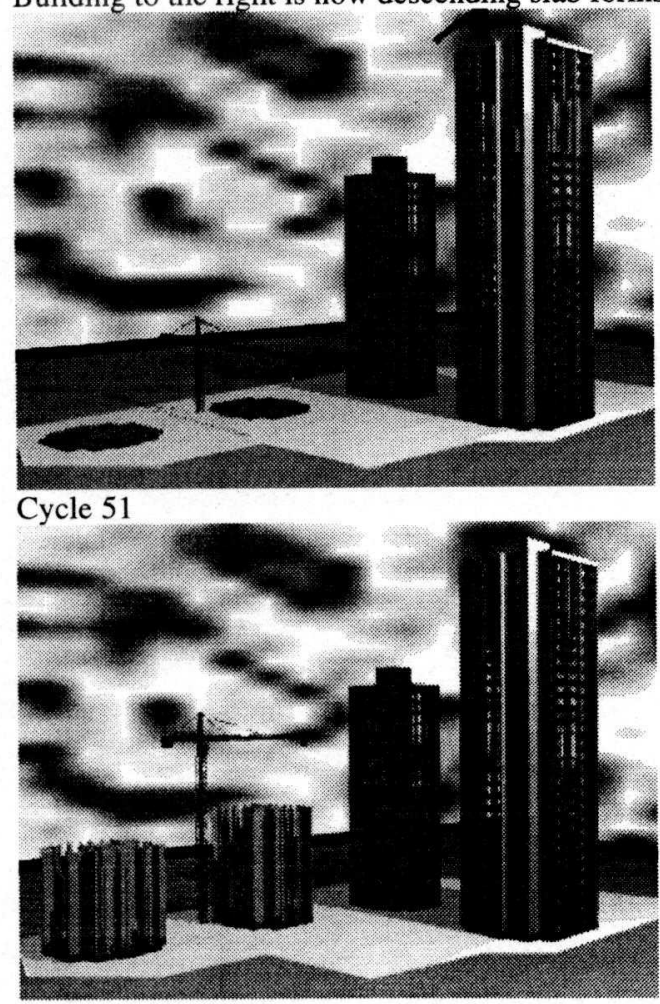

Cycle 61: Building to the right is finished.
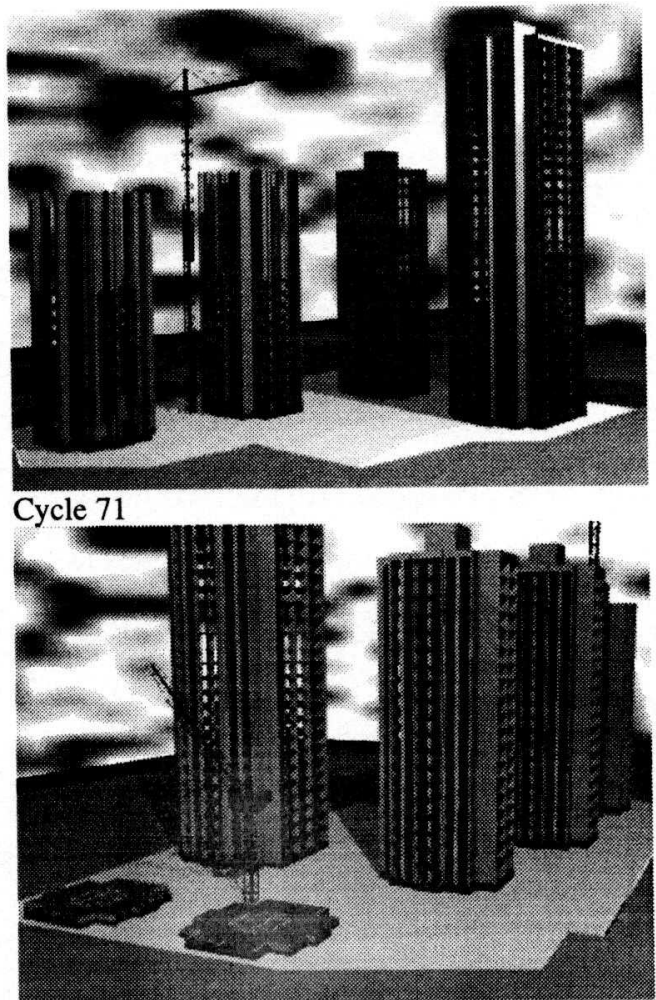

Cycle 81: Another two buildings starts excavation. A different type of tower crane is used.
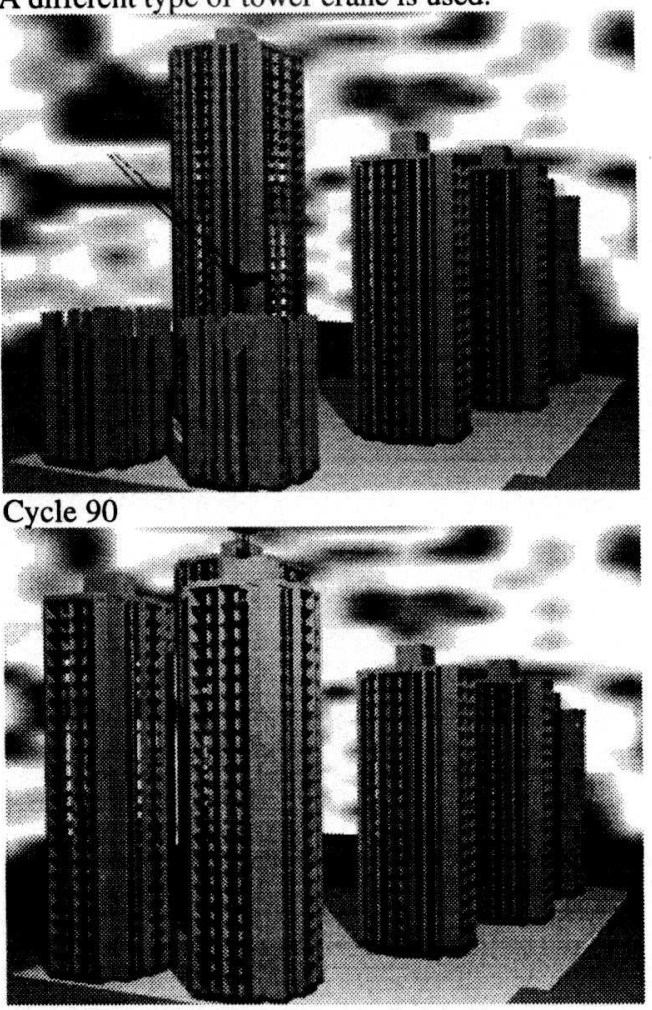

Cycle 113: All structures are finished. 